\title{
Preoperative neutrophil-to-lymphocyte ratio as a prognostic predictor after curative-intent surgery for hepatocellular carcinoma: experience from a developing country
}

This article was published in the following Dove Press journal:

Cancer Management and Research

\author{
Danijel Galun ${ }^{1,2}$ \\ Aleksandar Bogdanovic' \\ Jelena Djokic Kovac ${ }^{2,3}$ \\ Predrag Bulajic' \\ Zlatibor Loncar ${ }^{2,4}$ \\ Marinko Zuvela ${ }^{1,2}$ \\ 'HPB Unit, Clinic for Digestive \\ Surgery, Clinical Center of Serbia, \\ Belgrade, Serbia; ${ }^{2}$ Medical School, \\ University of Belgrade, Belgrade, \\ Serbia; ${ }^{3}$ Center for Radiology and \\ Magnetic Resonance Imaging, Clinical \\ Center of Serbia, Belgrade, Serbia; \\ ${ }^{4}$ Emergency Center, Clinical Center of \\ Serbia, Belgrade, Serbia
}

Purpose: The aim of the study was to evaluate a prognostic value of preoperative neutrophilto-lymphocyte ratio (NLR) on long-term survival of cirrhotic and noncirrhotic hepatocellular cancer (HCC) patients managed by a curative-intent liver surgery in a developing country.

Patients and methods: During the study period between November 1, 2001, and December 31, 2012, 109 patients underwent potentially curative hepatectomy for HCC. Data were retrospectively reviewed from the prospectively collected database. The median follow-up was 25 months. NLR was estimated by dividing an absolute neutrophil count by an absolute lymphocyte count from the differential blood count. Receiver operating characteristic curve was constructed to assess the ability of NLR to predict long-term outcomes and to determine an optimal cutoff value for all patients group, the subgroup with cirrhosis, and the subgroup without cirrhosis. The optimal cutoff values were $1.28,1.28$, and 2.09 , respectively.

Results: The overall 3- and 5-year survival rates were $49 \%$ and $45 \%$, respectively, for low NLR group and $38 \%$ and $26 \%$, respectively, for high NLR group. The difference was statistically significant $(p=0.015)$. Overall survival was similar between low and high NLR groups in patients with cirrhosis; no difference was found between the groups $(p=0.124)$. In patients without cirrhosis, low NLR group had longer overall survival compared with high NLR group $(p=0.015)$. Univariate analysis identified four factors as significant predictors of long-term survival: cirrhosis, Child-Pugh score, platelet count, and NLR. On multivariate analysis, only platelet count and NLR were independent prognostic factors of long-term survival.

Conclusion: Prognostic value of NLR was confirmed in noncirrhotic HCC patients who underwent curative-intent liver surgery. In HCC patients with cirrhosis, the prognostic role of NLR was not confirmed.

Keywords: neutrophil-to-lymphocyte ratio, hepatocellular carcinoma, cirrhosis, inflammation, liver resection

\section{Introduction}

Hepatocellular cancer (HCC) is one of the leading causes of cancer-related deaths., ${ }^{1,2}$ It is characterized by growing incidence worldwide mainly due to rising number of patients with metabolic syndrome and viral hepatitis. ${ }^{1-4}$ Due to late diagnosis, low resectability rate, high recurrence after a curative-intent surgery, and poor response to medical treatments are often associated with a grave outcome. ${ }^{3-6}$

According to the HCC staging system proposed by the Barcelona-Clinic Liver Cancer Group and endorsed by the European and American Association for the
Correspondence: Danijel Galun Clinic for Digestive Surgery, Clinical Center of Serbia, Koste Todorovica 6, Belgrade 11000 , Serbia

Tel +38I I| 36I 5652

$\mathrm{Fax}+381$ II 3615655

Email galun95@gmail.com 
Study of the Liver (EASL, AASLD), hepatic resection is allocated to patients with early stage HCC and satisfactory liver function. ${ }^{7}$ Several centers have shown that hepatic resection is justified even for the advanced-stage disease, that is, for the large and multinodular HCC..$^{8-11}$ Despite modern diagnostic and therapeutic approaches, the longterm prognosis of $\mathrm{HCC}$ remains poor. The application of sensitive prognostic biomarkers to better select the best candidates for curative-intent treatment options is important for daily clinical practice.

$\mathrm{HCC}$ is one of the inflammation-induced cancers. Inflammatory microenvironment caused by viral hepatitis, alcoholic and nonalcoholic steatohepatitis has a critical role in modulating liver fibrosis, cirrhosis, epithelial-mesenchymal transition, tumor invasion, and metastasis. ${ }^{12}$ Recent evidence indicates that systemic inflammatory response correlates with worse prognosis in HCC patients. ${ }^{13-15}$ Neutrophil-tolymphocyte ratio (NLR) is an appropriate, readily measurable from differential blood count, and inexpensive biomarker of inflammatory process. A ratio between neutrophils, a marker of tumor-promoting inflammation, and lymphocytes, as part of antitumor immunity, indicates the balance between these two processes. ${ }^{16}$

Several studies published in the literature have shown a prognostic value of NLR in colorectal cancer, gastric cancer, lung cancer, and pancreatic cancer. ${ }^{17-20}$ In HCC patients, NLR has been suggested as a prognostic marker at different stages of the disease. ${ }^{21-25}$ The vast majority of published reports are large population-based studies from Asia having high percentage of chronic hepatitis B virus-infected patients. ${ }^{21,26-29}$ Contrary to that, in developed countries of the western world, HCC is dominantly related to chronic hepatitis $\mathrm{C}$ virus (HCV) infection and metabolic syndrome that have a rising incidence. ${ }^{30,31}$ Studies from developing countries, assessing the prognostic value of NLR, are lacking. This is important due to high percentage of noncirrhotic HCC patients in developing countries. Several studies, comparing surgical outcome of noncirrhotic and cirrhotic HCC patients, reported a high percentage of $\mathrm{HCC}$ in patients without underlying liver disease, ranging between $19 \%$ and $26 \% .^{32,33}$

The aim of this study was to evaluate a prognostic value of preoperative NLR on long-term survival of cirrhotic and noncirrhotic HCC patients managed by a curative-intent liver surgery. While it was expected that prognostic value of NLR would be confirmed in patients with cirrhosis due to inflammatory microenvironment, NLR in noncirrhotic patients was expected to lack any prognostic value.

\section{Patients and methods}

During the study period between November 1, 2001, and December 31, 2012, a total of 109 patients underwent potentially curative hepatectomy for HCC. Data were retrospectively reviewed from the prospectively collected database of 692 patients who underwent liver resection for various indications in the aforementioned period at the University Clinic for digestive surgery, Unit for hepato-bilio-pancreatic surgery. The exclusion criteria were transarterial chemoembolization, radiofrequency ablation, or chemotherapy prior to surgery, repeated liver resection, immunological or hematological disease, and current infection (Figure 1).

\section{Preoperative evaluation}

All patients underwent laboratory testing (differential blood count, biochemistry, coagulation status, viral serology), transabdominal ultrasound, computed tomography (CT) and/or magnetic resonance (MR), preoperative cardiologic and anesthesiology risk assessments. Liver cirrhosis was confirmed considering serology, imaging, and pathohistology. Degree of liver cirrhosis was determined by Child-Pugh score. HCC diagnosis was established according to EASL Clinical Practice Guidelines. ${ }^{34}$

Demographic and clinicopathologic data including age, sex, American Society of Anesthesiologists (ASA) score, presence of cirrhosis, etiology of cirrhosis, Child-Pugh score, laboratory parameters (white blood cells count, platelet count, total serum bilirubin, alanine aminotransferase), tumor number and size, and the extent of hepatectomy were collected and presented in Table 1 (comparison between cirrhosis and noncirrhosis HCC groups) and Table 2 (comparison between low and high NLR groups).

\section{Surgery}

Radiofrequency-assisted sequential "coagulate-cut" liver resection technique was performed in all patients who underwent liver resection. ${ }^{35,36}$ Type of liver resection was defined according to Brisbane Terminology of liver anatomy and resections. ${ }^{37}$ Major liver resection was defined as resection of three or more liver segments.

\section{Follow-up}

The median follow-up was 25 months. Follow-up visits included routine laboratory test, $\alpha$-feto protein measurement, and transabdominal ultrasonography every 3 months, and CT/MR every 6 months. After the 3-year follow-up, patients were screened twice yearly, and after 


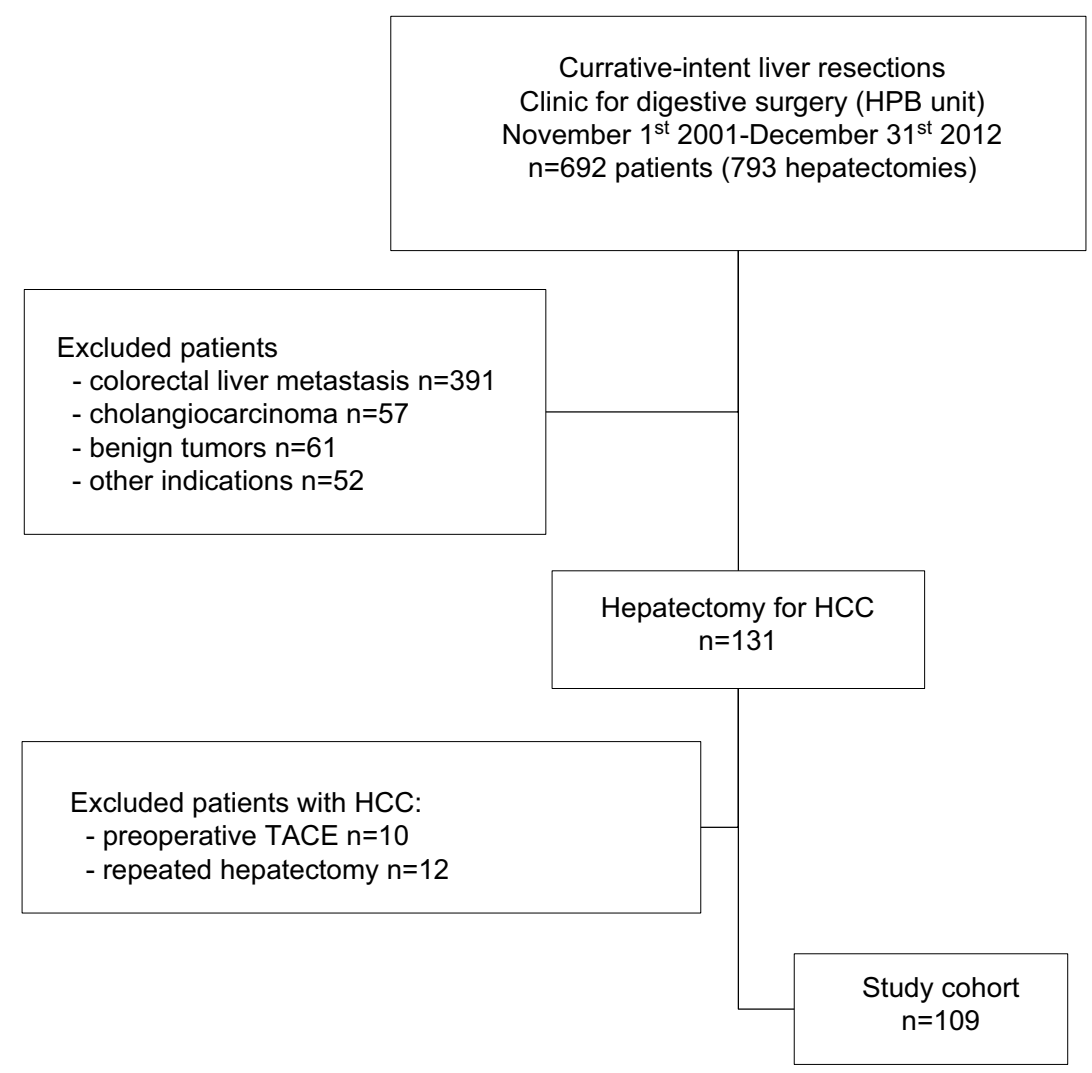

Figure I Patient flow diagram.

Abbreviations: HCC, hepatocellular carcinoma; HPB, hepato-pancreato-biliary; TACE, transarterial chemoembolization.

Table I Comparison of demographic, clinicopathologic, and laboratory data in cirrhosis- and noncirrhosis HCC groups

\begin{tabular}{|c|c|c|c|c|}
\hline Variables & Total, $n=109$ & $\begin{array}{l}\text { Cirrhosis group, } \\
n=62\end{array}$ & $\begin{array}{l}\text { Noncirrhosis group, } \\
n=47\end{array}$ & $p$ \\
\hline Age (years), median (range) & $66(18-82)$ & $66(42-82)$ & $65(18-80)$ & 0.070 \\
\hline \multicolumn{5}{|l|}{ Sex, n (\%) } \\
\hline Male & $65(59.6)$ & $35(56.5)$ & $30(63.8)$ & \multirow[t]{2}{*}{0.437} \\
\hline Female & $44(40.4)$ & $27(43.5)$ & $17(36.2$ & \\
\hline \multicolumn{5}{|l|}{ ASA, n (\%) } \\
\hline $\mathrm{I} / \mathrm{II}$ & $62(56.9)$ & $32(51.6)$ & $30(63.8)$ & \multirow[t]{2}{*}{0.202} \\
\hline III/IV & $47(43.1)$ & $30(48.4)$ & $17(36.2)$ & \\
\hline \multicolumn{5}{|l|}{ Etiology, n (\%) } \\
\hline HBV & $30(27.5)$ & $30(27.5)$ & - & \\
\hline $\mathrm{HCV}$ & $23(21.1)$ & $23(21.1)$ & - & \\
\hline Alcohol abuse & $6(5.5)$ & $6(5.5)$ & - & \\
\hline Other (unknown) & $3(2.8)$ & $3(2.8)$ & - & \\
\hline Liver steatosis & $17(15.6)$ & - & $17(36.2)$ & \\
\hline Alcohol excess & $2(1.8)$ & - & $2(4.2)$ & \\
\hline Adenoma alteration & $5(4.6)$ & - & $5(10.6)$ & \\
\hline WBC $\left(\times 10^{9} / L\right)$, median (range) & $6.7(2-11)$ & $6.5(2-10)$ & $7(4-I I)$ & 0.662 \\
\hline Platelet ( $\left.\times 10^{9} / L\right)$, median (range) & $210(42-583)$ & $210(42-427)$ & $218(123-583)$ & 0.158 \\
\hline NLR, median (range) & $1.95(0.37-6.07)$ & $2.04(0.63-6.07)$ & $1.74(0.37-5.78)$ & 0.520 \\
\hline PLR, median (range) & $107.5(11.2-647.8)$ & $107.5(20.1-266.9)$ & $98.4(11.2-647.8)$ & 0.343 \\
\hline Total bilirubin (mmol/L), median (range) & $12.5(3.8-636)$ & $15(3.8-636)$ & II (4-26) & 0.149 \\
\hline ALT (IU/L), median (range) & $32(6-166)$ & $35(6-166)$ & $29(11-158)$ & 0.311 \\
\hline$\gamma$ GT (IU/L), median (range) & $59(9-1185)$ & $68.5(9-1185)$ & $53(|0-87|)$ & 0.490 \\
\hline \multicolumn{5}{|l|}{ Lesion number, $\mathrm{n}(\%)$} \\
\hline Single & $95(87.2)$ & $52(83.9)$ & $43(91.5)$ & 0.239 \\
\hline Multiple & $14(12.8)$ & $10(16.1)$ & $4(8.5)$ & \\
\hline
\end{tabular}


Table I (Continued)

\begin{tabular}{|c|c|c|c|c|}
\hline Variables & Total, $\mathrm{n}=109$ & $\begin{array}{l}\text { Cirrhosis group, } \\
n=62\end{array}$ & $\begin{array}{l}\text { Noncirrhosis group, } \\
n=47\end{array}$ & $p$ \\
\hline \multicolumn{5}{|l|}{ Major lesion size, $\mathrm{n}(\%)$} \\
\hline$<5 \mathrm{~cm}$ & $12(11)$ & $7(11.3)$ & $5(10.6)$ & 0.914 \\
\hline$\geq 5 \mathrm{~cm}$ & $97(89)$ & $55(88.7)$ & $42(89.4)$ & \\
\hline Operative time (min), median (range) & $240(55-600)$ & $240(55-600)$ & $300(120-480)$ & 0.373 \\
\hline Transection time (min), median (range) & $60(15-210)$ & $60(15-210)$ & $60(15-210)$ & 0.745 \\
\hline \multicolumn{5}{|l|}{ Hepatectomy, n (\%) } \\
\hline Anatomic & $52(47.7)$ & $29(46.8)$ & $23(48.9)$ & 0.823 \\
\hline Nonanatomic & $57(52.3)$ & $33(53.2)$ & $24(51.1)$ & \\
\hline \multicolumn{5}{|l|}{ Extent of resection, $\mathrm{n}(\%)$} \\
\hline Major & $39(35.8)$ & $20(32.3)$ & $19(40.4)$ & 0.378 \\
\hline Minor & $70(64.2)$ & $42(67.7)$ & $28(59.6)$ & \\
\hline Intraoperative transfusion rate, $\mathrm{n}(\%)$ & $7(6.4)$ & $2(3.2)$ & $5(10.6)$ & 0.235 \\
\hline
\end{tabular}

Abbreviations: $\gamma \mathrm{GT}$, gamma-glutamyl transferase; ALT, alanine aminotransferase; ASA, American Society of Anesthesiologists; HBV, hepatitis B virus; HCC, hepatocellular cancer; HCV, hepatitis C virus; NLR, neutrophil-to-lymphocyte ratio; PLR, platelet to lymphocyte ratio; WBC, white blood cells.

Table 2 Comparison of demographic, clinicopathologic, and laboratory data in low and high NLR groups

\begin{tabular}{|c|c|c|c|c|}
\hline Variables & Total, $n=109$ & Low NLR group, $n=34$ & High NLR group, $n=75$ & $p$ \\
\hline Age (years), median (range) & $66(18-82)$ & $64(2 I-8 I)$ & $66(18-82)$ & 0.341 \\
\hline \multicolumn{5}{|l|}{ Sex, n (\%) } \\
\hline Male & $65(59.6)$ & $19(55.9)$ & $46(61.3)$ & \multirow[t]{2}{*}{0.675} \\
\hline Female & $44(40.4)$ & $15(44.1)$ & $29(38.7)$ & \\
\hline \multicolumn{5}{|l|}{ ASA, n (\%) } \\
\hline $\mid / I I$ & $62(56.9)$ & I8 (52.9) & $44(58.7)$ & \multirow[t]{2}{*}{0.677} \\
\hline $\mathrm{III} / \mathrm{IV}$ & $47(43.1)$ & $16(47.1$ & $3 I(4 I .3)$ & \\
\hline \multicolumn{5}{|l|}{ Cirrhosis, n (\%) } \\
\hline No & $47(43.1)$ & $18(52.9)$ & $29(38.7)$ & \multirow[t]{2}{*}{0.211} \\
\hline Yes & $62(56.9)$ & $16(47.1)$ & $46(61.3)$ & \\
\hline \multicolumn{5}{|l|}{ Etiology, n (\%) } \\
\hline HBV & $30(27.5)$ & $8(23.5)$ & $22(29.3)$ & \multirow[t]{4}{*}{0.668} \\
\hline $\mathrm{HCV}$ & $23(2 I . I)$ & $5(14.7)$ & $18(24)$ & \\
\hline Alcohol abuse & $6(5.5)$ & $2(5.9)$ & $4(5.3)$ & \\
\hline Others & $3(2.8)$ & $\mathrm{I}(2.9)$ & $2(2.7)$ & \\
\hline \multicolumn{5}{|l|}{ Child-Pugh score, n (\%) } \\
\hline A & $47(75.8)$ & $12(35.3)$ & $35(46.7)$ & \multirow[t]{2}{*}{0.377} \\
\hline B & $15(24.2)$ & $4(11.8)$ & II (I4.7) & \\
\hline WBC $\left(\times 10^{9} / L\right)$, median (range) & $6.7(2.2-20.4)$ & $5.6(2.2-20.4)$ & $7.1(2.8-14.2)$ & 0.045 \\
\hline Platelet $\left(\times 10^{9} / \mathrm{L}\right)$, median (range) & $210(42-583)$ & $192(91-427)$ & $233(42-583)$ & 0.021 \\
\hline Total bilirubin (mmol/L), median (range) & $12.5(3.6-636)$ & $12.5(3.6-636)$ & $12.5(5.2-1 \mid 5)$ & 0.392 \\
\hline ALT (IU/L), median (range) & $32(6-166)$ & $32(6-116)$ & $30(6-166)$ & 0.753 \\
\hline$\gamma \mathrm{GT}(\mathrm{IU} / \mathrm{L})$, median (range) & $59(9-1185)$ & $59(14-1185)$ & $58.5(9-470)$ & 0.154 \\
\hline \multicolumn{5}{|l|}{ Lesion number, $\mathrm{n}(\%)$} \\
\hline Single & $95(87.2)$ & 31 (9l.2) & $64(85.3)$ & \multirow[t]{2}{*}{0.542} \\
\hline Multiple & $14(12.8)$ & $3(8.8)$ & II (14.7) & \\
\hline \multicolumn{5}{|l|}{ Major lesion size, n (\%) } \\
\hline$<5 \mathrm{~cm}$ & $12(11)$ & $5(14.7)$ & $7(9.3)$ & \multirow[t]{2}{*}{0.51} \\
\hline$\geq 5 \mathrm{~cm}$ & $97(89)$ & $29(85.3)$ & $68(90.7)$ & \\
\hline \multicolumn{5}{|l|}{ Hepatectomy, n (\%) } \\
\hline Anatomic & $52(47.7)$ & $17(50)$ & $35(46.7)$ & \multirow[t]{2}{*}{0.837} \\
\hline Nonanatomic & $57(52.3)$ & $17(50)$ & $40(53.3)$ & \\
\hline \multicolumn{5}{|l|}{ Extent of resection, $\mathrm{n}(\%)$} \\
\hline Major & $39(35.8)$ & $9(26.5)$ & $30(40)$ & \multirow[t]{2}{*}{0.2} \\
\hline Minor & $70(64.2)$ & $25(73.5)$ & $45(60)$ & \\
\hline
\end{tabular}

Note: Values shown in bold indicate a statistically significant difference between the groups $(p<0.05)$.

Abbreviations: $\gamma \mathrm{GT}$, gamma-glutamyl transferase; ALT, alanine aminotransferase; ASA, American Society of Anesthesiologists; HBV, hepatitis B virus; HCV, hepatitis C virus; NLR, neutrophil-to-lymphocyte ratio; WBC, white blood cells. 
5th year, annually. The recurrence limited to the liver only, was treated by repeated liver resection, RF ablation, or chemoembolization.

\section{Receiver operating characteristic curve analysis}

NLR was estimated by dividing an absolute neutrophil count by an absolute lymphocyte count from the differential blood count. Receiver operating characteristic (ROC) curve was constructed for the assessability of NLR to predict longterm outcomes and to determine an optimal cutoff value for total group, as well for the subgroup with cirrhosis and the subgroup without cirrhosis (Figure 1). Depending on NLR, patients were subsequently divided into a low and a high NLR groups. The overall survival (OS) was compared between the groups.

\section{Statistical analysis}

Continuous variables were expressed as median and range and compared using the Student's $t$-test. Categorical variables were compared using the $\chi^{2}$-test or Fisher's exact test. OS curves were estimated using the Kaplan-Meier method and compared using the log-rank test. The Cox proportional hazards model was used for univariate and multivariate analyses. Significant predictor factors at univariate analysis were consecutively analyzed by multivariate analysis. $P$-value $\leq 0.05$ was considered statistically significant. SPSS for Windows (SPSS Inc., Chicago, IL, USA) version 18.0 was used for statistical analyses.

The study was approved by the Ethics Committee of the Clinical center of Serbia, Ethics Committee of the Medical School, University of Belgrade.

All patients have given their written informed consent.

\section{Results}

\section{Demographic data}

During the study period, 109 patients with HCC underwent potentially curative resection. The median age was 66 (range, 18-82) years, and there were 65 male and 44 female patients. Liver cirrhosis was present in 62 patients (56.9\%). Viral hepatitis was a dominant cause of cirrhosis and was present in 53 patients (hepatitis $\mathrm{C}$ in 23 , hepatitis $\mathrm{B}$ in 30, and alcohol abuse in 6 and other causes in 3 patients). Liver steatosis was a dominant feature in noncirrhosis HCC patients (17 patients); other etiology included alcohol excess ( 2 patients) and hepatocellular adenoma alteration (5 patients; Tables 1 and 2 ).

\section{Surgical procedures}

Majority of patients had a solitary tumor (95 patients); multiple tumors were present in $12.8 \%$ of patients. A tumor $>5 \mathrm{~cm}$ in diameter was present in 97 patients $(89 \%)$.

The major liver resection was performed in 39 patients. The resection of less than three liver segments was performed in $64.2 \%$ of patients.

The overall morbidity was $38 \%$, and there were three in-hospital deaths (postoperative mortality $2.7 \%$ ). The most common complication was intraabdominal infection followed by respiratory complications. Five patients developed liver insufficiency postoperatively, and transient renal failure was reported in one patient (Table 3).

\section{NLR analysis}

A total of white blood cells count and platelet count were greater in high NLR group than in low NLR group ( $p=0.045$; $p=0.021$ ). Both groups were similar regarding age, sex, ASA score, cirrhosis, etiology of cirrhosis, Child-Pugh score, total serum bilirubin, alanine aminotransferase, tumor number and size, and the extent of hepatectomy (Table 1).

The optimal cutoff values for all patients group, patient subgroup with cirrhosis, and patient subgroup without cirrhosis were 1.28, 1.28, and 2.09, respectively (Figure 2). The overall 3- and 5-year survival of patients with cirrhosis was significantly shorter than patients without cirrhosis $(35 \%$ and $26 \%$ vs $49 \%$ and $42 \%$, respectively; $p=0.004$; Figure 3 ).

Table 3 Comparison of postoperative morbidity between cirrhosis and noncirrhosis groups

\begin{tabular}{|c|c|c|c|c|}
\hline Variables & $\begin{array}{l}\text { Total, } \\
\mathrm{n}=109\end{array}$ & $\begin{array}{l}\text { Cirrhosis, } \\
n=62\end{array}$ & $\begin{array}{l}\text { Noncirrhosis, } \\
n=47\end{array}$ & $p$ \\
\hline Morbidity, n (\%) & $41(37.6)$ & $29(46.8)$ & $12(25.5)$ & 0.029 \\
\hline Major morbidity, n (\%) & $18(16.5)$ & $10(16.1)$ & $8(17)$ & 0.901 \\
\hline \multicolumn{5}{|c|}{ Liver-related complications, n (\%) } \\
\hline $\begin{array}{l}\text { Infected perihepatic } \\
\text { collection }\end{array}$ & $10(9.2)$ & $3(4.8)$ & $7(14.9)$ & 0.071 \\
\hline Liver insufficiency & $5(4.6)$ & $4(6.4)$ & $\mathrm{I}(2 . \mathrm{I})$ & 0.387 \\
\hline Biliary leakage & $7(6.4)$ & $2(2.8)$ & $5(10.6)$ & 0.235 \\
\hline Hemorrhage & I (0.9) & $\mathrm{I}(\mathrm{I} .6)$ & 0 & 0.382 \\
\hline \multicolumn{5}{|c|}{ General complications, n (\%) } \\
\hline $\begin{array}{l}\text { Respiratory } \\
\text { complications }\end{array}$ & $8(7.3)$ & $4(6.4)$ & $4(8.5)$ & 0.724 \\
\hline Renal failure & I (0.9) & $\mathrm{I}(\mathrm{I} .6)$ & - & 0.382 \\
\hline $\begin{array}{l}\text { Cardiovascular } \\
\text { complications }\end{array}$ & $2(1.8)$ & $\mathrm{I}(\mathrm{I} .6)$ & $\mathrm{I}(2.1)$ & 1 \\
\hline Relaparotomy, n (\%) & I (0.9) & $\mathrm{I}(\mathrm{I} .6)$ & - & 0.382 \\
\hline Mortality, n (\%) & $3(2.7)$ & $2(2.8)$ & $\mathrm{I}(2.1)$ & 0.742 \\
\hline $\begin{array}{l}\text { Postoperative hospital } \\
\text { stay, median (range) }\end{array}$ & $\begin{array}{l}12.5 \\
(2-52)\end{array}$ & $13(2-52)$ & $12(4-49)$ & 0.902 \\
\hline
\end{tabular}

Note: Values shown in bold indicate a statistically significant difference between the groups $(p<0.05)$. 
A

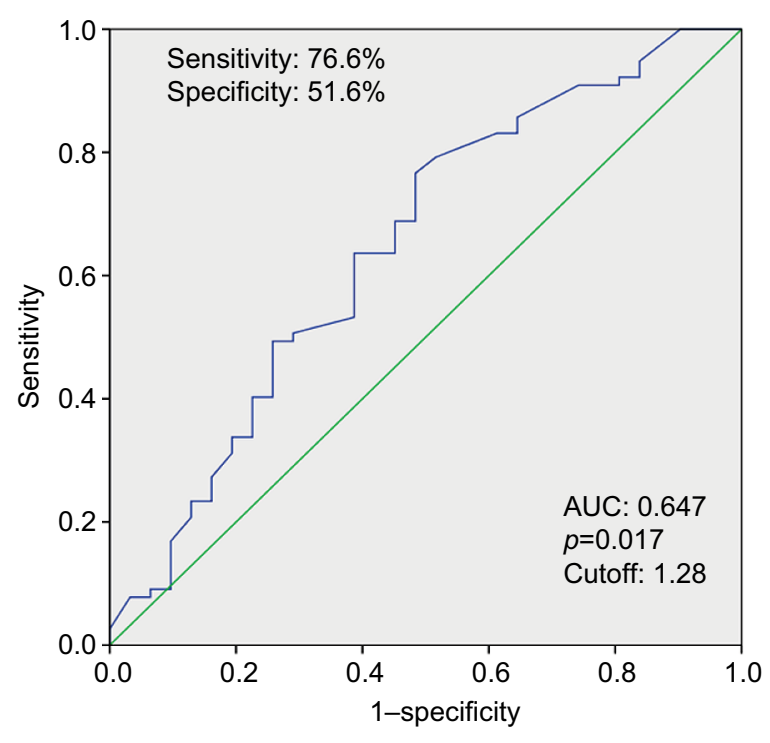

B

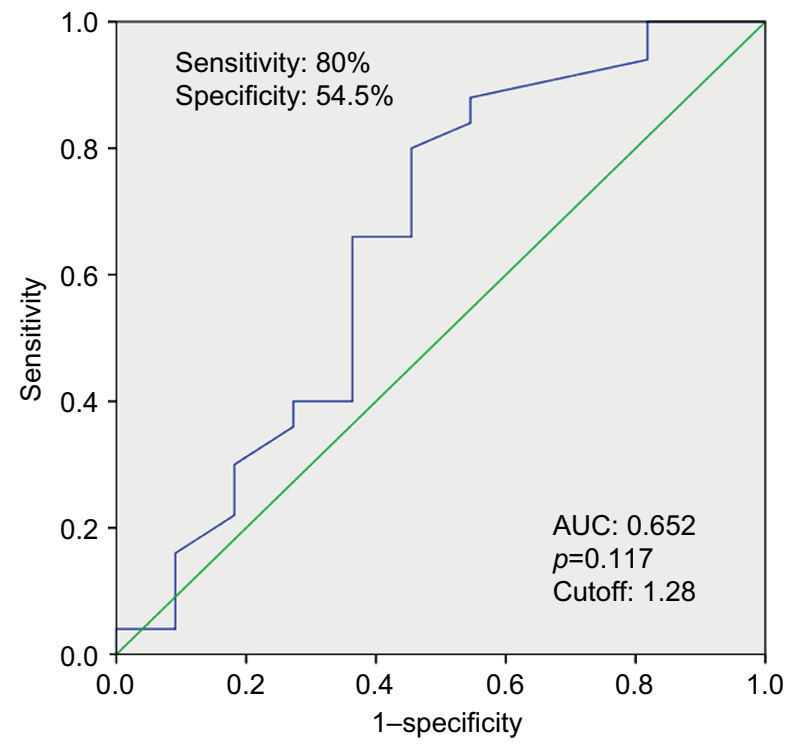

C

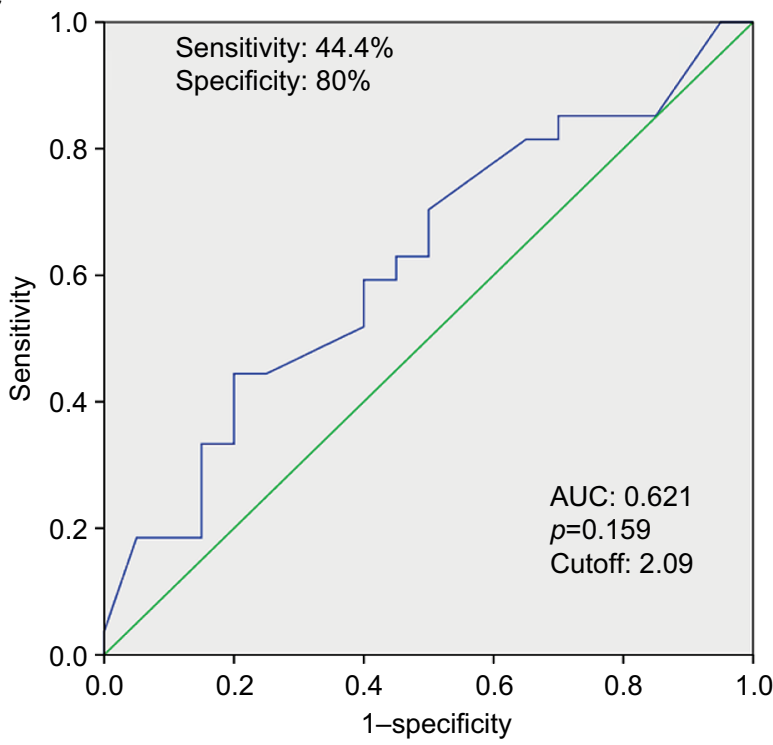

Figure 2 ROC curve analysis for neutrophil-lymphocyte ratio. (A) All patients group; (B) subgroup with cirrhosis; (C) subgroup without cirrhosis. Abbreviations: AUC, area under the curve; ROC, receiver operating characteristic.

\section{Analysis of prognostic factors}

By univariate analysis, four factors were identified as significant predictors of OS: presence of cirrhosis, ChildPugh score B, low platelet count $\left(<100 \times 10^{9} / \mathrm{L}\right)$, and NLR. The significant predictors were then used for a multivariate analysis; only platelet count $(p<0.001, \mathrm{HR}=5.050,95 \% \mathrm{CI}$ : $1.861-13.702)$ and NLR $(p<0.024, \mathrm{HR}=1.865,95 \% \mathrm{CI}$ : 1.086-3.203) were independent prognostic factors of OS (Table 4).

\section{Impact of NLR on overall survival}

The overall 3- and 5-year survival rates of low NLR group were $49 \%$ and $45 \%$, respectively. In contrast, 3 - and 5-year survival rates of high NLR group were $38 \%$ and $26 \%$, respectively. The difference was statistically significant $(p=0.015$; Figure 4A).

OS was similar between low and high NLR groups in patients with cirrhosis ( $p=0.124$; Figure $4 \mathrm{~B}$ ).

In patients without cirrhosis, low NLR group had longer OS compared with high NLR group ( $p=0.015$; Figure $4 C$ ).

\section{Discussion}

There are two important highlights of the presented study. The first is that it confirmed the prognostic role of NLR in HCC population from a developing country characterized by high percentage of noncirrhotic HCC patients. The second is that it analyzed the prognostic role of NLR in cirrhotic and noncirrhotic patients separately. 


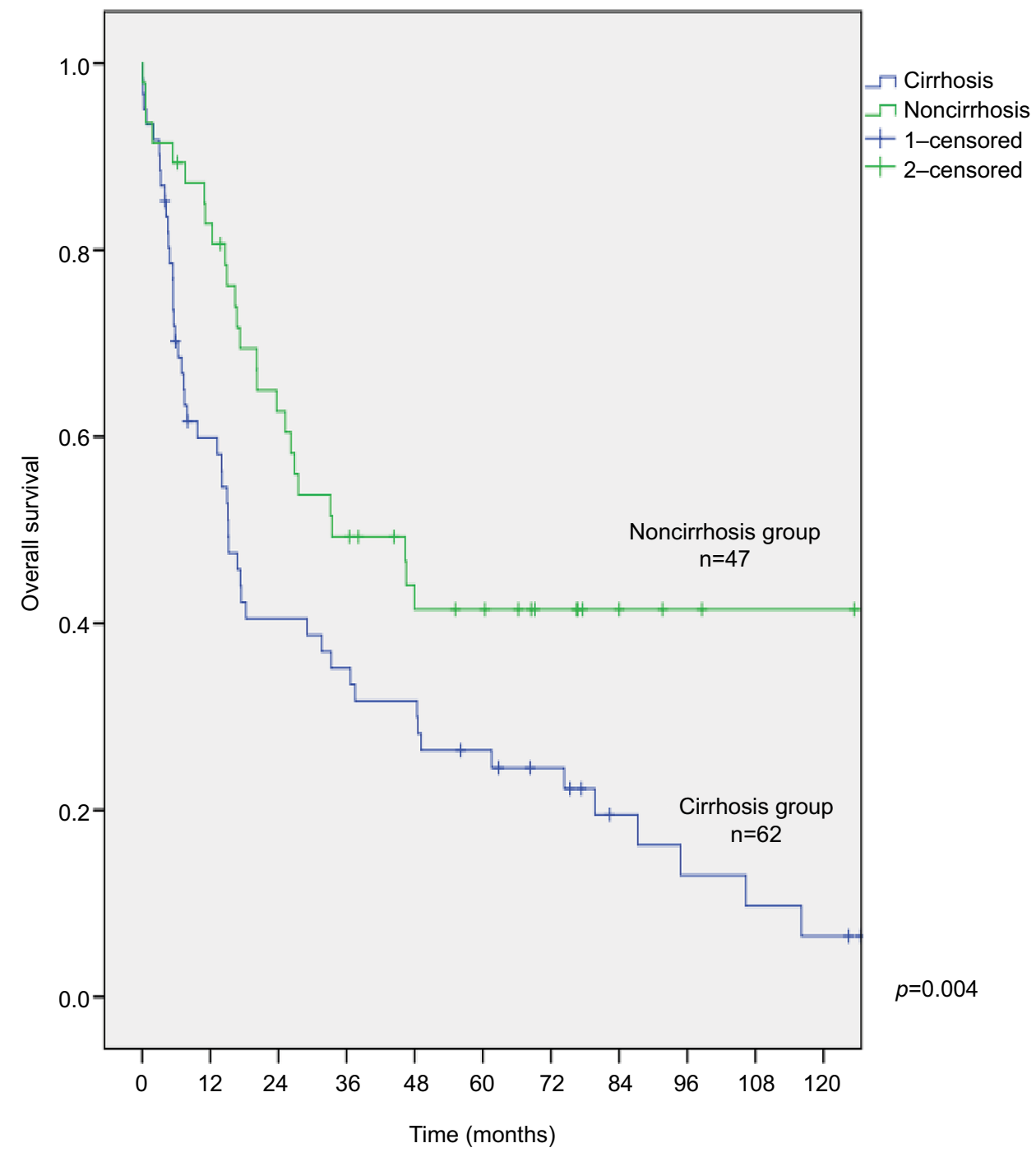

Figure 3 Survival function curves for patients with and without cirrhosis.

Table 4 Univariate and multivariate analyses of prognostic factors

\begin{tabular}{|c|c|c|c|c|c|c|}
\hline \multirow[t]{2}{*}{ Variable } & \multicolumn{3}{|c|}{ Univariate analysis } & \multicolumn{3}{|c|}{ Multivariate analysis } \\
\hline & HR & $95 \% \mathrm{Cl}$ & $p$ & HR & $95 \% \mathrm{Cl}$ & $p$ \\
\hline Sex (female) & 1.187 & $0.749-1.879$ & 0.466 & & & \\
\hline Age ( $\geq 65$ years) & 1.118 & $0.708-1.766$ & 0.632 & & & \\
\hline HBV & 1.329 & $0.819-2.159$ & 0.25 & & & \\
\hline $\mathrm{HCV}$ & 1.566 & $0.93 \mathrm{I}-2.635$ & 0.091 & & & \\
\hline Cirrhosis & 1.986 & $1.234-3.195$ & 0.005 & $\mathrm{I} .509$ & $0.9-2.532$ & 0.119 \\
\hline Child-Pugh (B) & 2.094 & $1.118-3.922$ & 0.021 & 1.856 & $0.948-3.636$ & 0.071 \\
\hline Platelets $\left(<100 \times 10^{9} / L\right)$ & 5.394 & $2.049-14.203$ & 0.001 & 5.050 & $1.861-13.702$ & 0.001 \\
\hline Bilirubin ( $\geq 25 \mu \mathrm{mol} / \mathrm{L})$ & 1.068 & $0.462-2.465$ & 0.878 & & & \\
\hline ALT ( $\geq 39$ IU/L) & $1.4 \mathrm{II}$ & $0.893-2.229$ & 0.141 & & & \\
\hline$\gamma \mathrm{GT}(\geq 55 \mathrm{IU} / \mathrm{L})$ & 0.919 & $0.583-1.447$ & 0.715 & & & \\
\hline NLR $(\geq 1.28)$ & 1.919 & $1.124-3.276$ & 0.017 & 1.865 & $1.086-3.203$ & 0.024 \\
\hline Tumor number (multiple) & 1.397 & $0.7|7-2.72|$ & 0.326 & & & \\
\hline Major lesion size $(\geq 5 \mathrm{~cm})$ & 1.688 & $0.730-3.899$ & 0.221 & & & \\
\hline Nonanatomic hepatectomy & 0.807 & $0.513-1.267$ & 0.351 & & & \\
\hline Intraoperative transfusion & 1.269 & $0.549-2.931$ & 0.577 & & & \\
\hline Major resection ( $\geq$ segments) & 1.382 & $0.865-2.209$ & 1.176 & & & \\
\hline
\end{tabular}

Note: Values shown in bold indicate a statistically significant difference between the groups $(p<0.05)$.

Abbreviations: $\gamma \mathrm{GT}$, gamma-glutamyl transferase; ALT, alanine aminotransferase; HBV, hepatitis B virus; HCV, hepatitis C virus; NLR, neutrophil-to-lymphocyte ratio. 

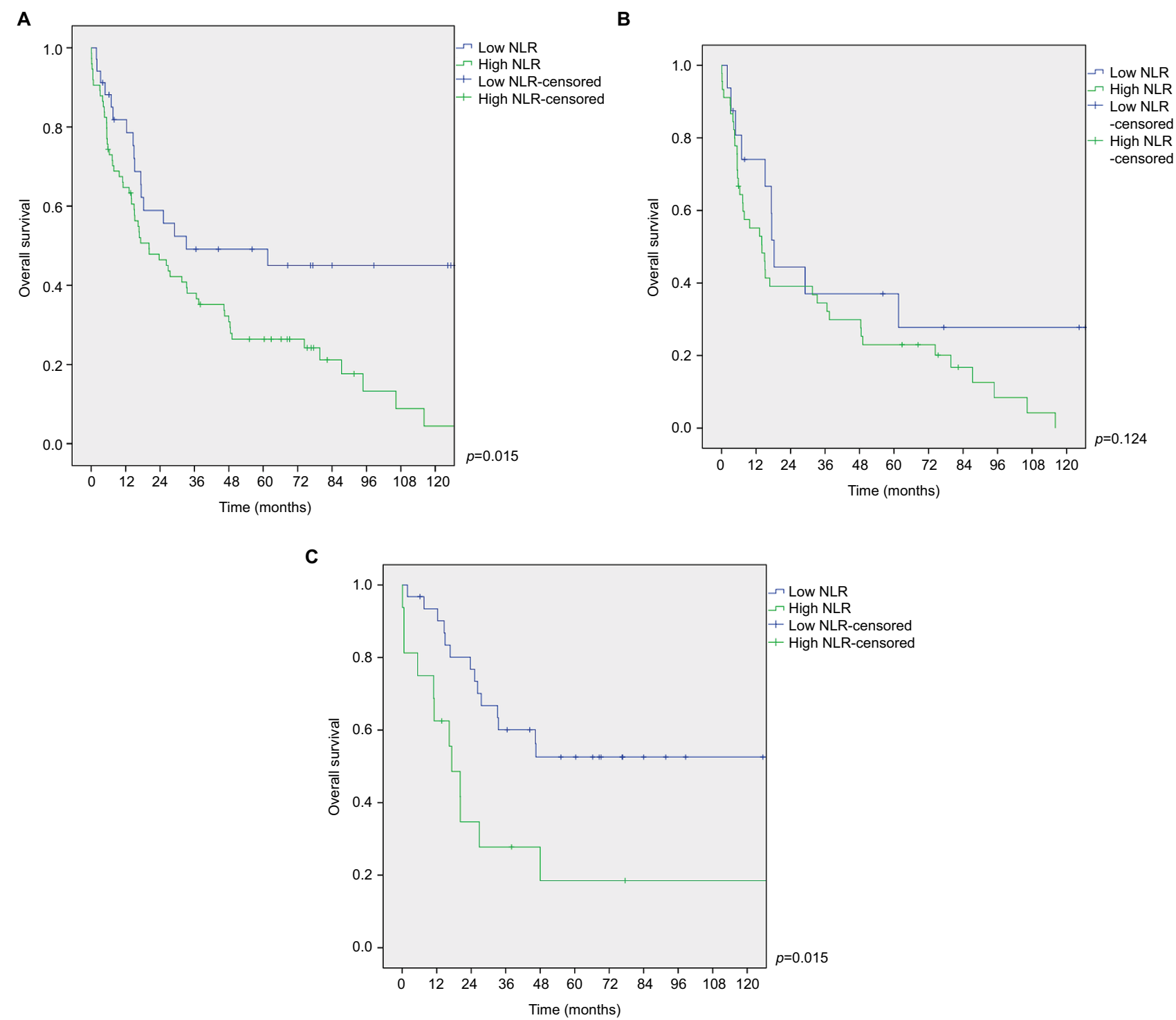

Figure 4 Survival function curves for low and high NLR groups. (A) All patients group; (B) subgroup with cirrhosis; (C) subgroup without cirrhosis Abbreviation: NLR, neutrophil-to-lymphocyte ratio.

The study results indicate that NLR is a good prognostic factor for noncirrhotic HCC patients since low NLR group had longer OS compared with high NLR group ( $p=0.015$ ).

However, in HCC patients with cirrhosis, OS was similar in both low and high NLR groups, that is, no difference was found between the two groups $(p=0.124)$. This result was surprising as liver cirrhosis represents an inflammatory microenvironment caused by viral hepatitis, alcoholic and nonalcoholic steatohepatitis. It was expected that the prognostic role of NLR would be confirmed in HCC patients with cirrhosis as it was found in other studies published in the literature. ${ }^{21,26-29,31}$

Sullivan et al have studied the prognostic role of NLR, model for end-stage liver disease, and Child-Pugh score in Western center and found no predictive value for NLR in HCC patients undergoing hepatectomy, liver transplantation, or transarterial chemoembolization. ${ }^{30}$ In the aforementioned study, Child-Pugh score had the best predictive role in HCC patients.

Bronson et al have studied the predictive value of NLR in HCC patients undergoing hepatectomy and found that preoperative NLR does not predict recurrence after liver resection in HCC patients. ${ }^{38}$

Disparate results published in the literature about predictive value of NLR in HCC patients demonstrate the complexity between tumor-promoting inflammation and antitumor immunity. The association between elevated preoperative NLR and poor outcome after liver resection remains unclear. Available data from the literature indicate that macrophages infiltration into tumors leads to increased tumor-associated macrophage activity resulting in neutrophilia and/or 
lymphocytopenia. ${ }^{26,39,40}$ Moreover, neutrophil count correlates with tumor cell adhesion to hepatic sinusoids and tumor cell motility, the two processes which may be connected to tumor metastasis. ${ }^{41,42}$ Circulating neutrophils secrete the majority of circulating vascular endothelial growth factor, which is a known proangiogenic factor involved in tumor development. ${ }^{43}$ It has been shown that neutrophils exhibit immunosuppressive activity as they suppress the cytotoxic activity of lymphocytes, natural killer cells, and activated $\mathrm{T}$ cells through the production of arginase, nitric oxide, and reactive oxygen species. ${ }^{44}$

Opposite to tumor-promoting inflammation is an antitumor immunity mediated by lymphocytes. It is known that lymphocytopenia is associated with decreased number of tumor-specific T cells, thus leading to compromised antitumor immunity. ${ }^{45}$ The association between lymphocytopenia and poor outcome was confirmed in studies on colorectal cancer. ${ }^{46,47}$ It was found that patients with weaker lymphocytic infiltration at tumor margins have worse prognosis. ${ }^{46,47}$ In patients with elevated NLR, tumor-related inflammation is relatively strong while antitumor immune response remains weak. This may explain dismal prognosis of HCC patients with elevated NLR.

In the presented study, the elevated NLR ratio was associated with the worse prognosis in noncirrhotic HCC patients, while no difference was found between low and high NLR in cirrhotic HCC patients. Clearly, HCCs arising in cirrhotic and noncirrhotic livers are two different disease entities. While alterations in the $\mathrm{p} 53$ pathway are important for the development of HCC in cirrhotic livers, alterations in cell cycle regulators are critical for $\mathrm{HCC}$ occurrence in noncirrhotic livers. ${ }^{48}$

In a study by Young et al, NLR had no prognostic benefit in noncirrhotic HCC patients while NLR predicted both overall and recurrence-free survival in $\mathrm{HCC}$ patients with cirrhosis. ${ }^{49}$ In the same study on 142 HCC patients who underwent liver resection, multivariate analysis has shown that factors significant at predicting OS in HCC patients without cirrhosis were the following: 1) need for blood transfusion and 2) patient age $>65$ years at resection. ${ }^{49}$ In the cirrhosis group, the factors that predicted poorer OS on univariate analysis were positive resection margin, microscopic vascular invasion, and an elevated NLR. However, none of these factors was significant on multivariate analysis. ${ }^{49}$ In a meta-analysis and systemic review by Zheng et al, NLR was a significant risk factor for predicting the OS regardless of the treatment modality that was analyzed (different curative and palliative treatment modalities were considered). However, most studies used Chinese populations, known for high percentage of hepatitis B liver cirrhosis. ${ }^{50}$

In the presented study, four factors were identified as significant predictors of long-term survival on univariate analysis: cirrhosis, Child-Pugh score, platelet, and NLR. On multivariate analysis, only platelet count and NLR were independent prognostic factors of long-term survival.

Wang et al have studied the prognostic value of NLR, platelet to lymphocyte ratio (PLR), and prognostic nutritional index in hepatitis B-associated HCC patients at different stages of fibrosis who underwent liver resection and found that only NLR remained a significant prognostic indicator after multivariate analysis. ${ }^{51}$ Moreover, data from this study showed that the impact of these three markers on outcome was more evident in Ishak stage 0-5 patients compared with Ishak stage 6 patients. ${ }^{51}$ These findings correlate with the results of the presented study confirming the prognostic value of elevated NLR in noncirrhotic HCC patients while no difference was found between low and high NLR in cirrhotic HCC patients. As suggested earlier, these observations may impose an understanding that enhanced systemic inflammatory response associated with elevated NLR may promote tumor progression in a liver that does not have end-stage fibrosis, that is, cirrhosis. ${ }^{51}$

In the presented study, liver steatosis was a dominant feature among patients in noncirrhotic HCC group. It is known that steatosis may be a risk factor for $\mathrm{HCC}$ development due to resultant oxidative stress and increased levels of oncogenic growth factors. ${ }^{52}$ Furthermore, oxidative stress induced by hepatic mitochondrial, peroxisomal, and microsomal reactive oxygen species results in apoptosis, necrosis, inflammation, hepatic stellate cell activation, proinflammatory cytokine expression, and cell proliferation. ${ }^{53,54}$ Since the surveillance program for viral hepatitis patients was not established during the study period, majority of patients with viral hepatitisassociated HCC were diagnosed when liver cirrhosis had already occurred. That is the main reason why hepatitis B patients were not found in noncirrhotic HCC group.

In a latest systematic review by Najjar et al, mixed findings were reported regarding the prognostic value of elevated preoperative NLR. Elevated NLR was associated with worse OS after hepatectomy for HCC in 8 studies out of 18 . This variability may be attributed to the heterogeneity of the studied groups (difference in the etiology of $\mathrm{HCC}$, liver resection for early stage $\mathrm{HCC}$ vs advanced stage $\mathrm{HCC}$, and the impact of preoperative loco-regional treatment modalities). The authors have indicated that the change in NLR from pre- to post-resection rather than the absolute pretreatment value has 
been shown to be sometimes correlated with worse outcomes in HCC patients undergoing LR. ${ }^{55}$

The clinical implication of these findings is the potential usefulness of reducing elevated NLR before curative-intent liver surgery in HCC patients without cirrhosis. Although there are no specific treatment modalities to reduce tumorrelated inflammation, one of the approaches may be a stringent antiviral therapy in HCC patients with chronic infection. It is known that persistent inflammation promotes tumor growth and metastasis. ${ }^{56}$ Another approach that was tested in colorectal cancer patients is the use of cyclooxygenase-2 inhibitors and vaccines that exhibit antiangiogenic activities and promote lymphocyte response to tumor. ${ }^{57,58}$ Other preoperative immune-potentiation therapies should be established to enhance antitumor immunity.

Future prospective, randomized trials are needed to confirm these observations and to guide further research in this field.

\section{Study limitations}

The study limitations are its retrospective design and scarcity in evaluation of other systemic inflammatory markers like levels of C-reactive protein, PLR, and alkaline phosphatase. ${ }^{59}$ Another limitation is low sensitivity of ROC curve analysis for subgroup without cirrhosis mainly due to high cutoff value, even though statistically significant difference in OS was found between low and high NLR groups. However, the results of this study supported the use of NLR in noncirrhotic HCC patients as a potentially valuable instrument in directing pre and postoperative therapies to these patients.

\section{Conclusion}

The study results confirmed the prognostic value of NLR in HCC population from a developing country. The prognostic value of NLR was found for noncirrhotic HCC patients who underwent curative-intent liver resection as the low NLR group had longer OS compared with the high NLR group. This is mainly relevant for developing countries characterized by a high percentage of noncirrhotic HCC patients. Although there are no specific therapeutic targets to modulate the expression of tumor-related inflammatory responses, future studies should examine the potential clinical benefit of preoperative reduction of elevated NLR.

The prognostic value of NLR was not confirmed for cirrhotic HCC patients since OS was similar in both the low and high NLR groups.

\section{Acknowledgments}

This study was supported by the Ministry of Science of Republic of Serbia grant no 41030.

\section{Disclosure}

The authors report no conflicts of interest in this work.

\section{References}

1. Torre LA, Siegel RL, Ward EM, Jemal A. Global Cancer Incidence and Mortality Rates and Trends--An Update. Cancer Epidemiol Biomarkers Prev. 2016;25:16-27.

2. National Cancer Institute. Cancer Trends Progress Report - 2009/2010 Update. Available from: URL: http://progressreport.cancer.gov/. Accessed 2015 March.

3. El-Serag HB, Rudolph KL. Hepatocellular carcinoma: epidemiology and molecular carcinogenesis. Gastroenterology. 2007;132: $2557-2576$

4. Galun D, Basaric D, Zuvela M, et al. Hepatocellular carcinoma: From clinical practice to evidence-based treatment protocols. World J Hepatol. 2015;7(20):2274-2291.

5. Nojiri S, Kusakabe A, Fujiwara $\mathrm{K}$ et al. Clinical factors related to long-term administration of sorafenib in patients with hepatocellular carcinoma. Cancer Manag Res. 2012;4: 423-429.

6. Nojiri S, Kusakabe A, Shinkai N, et al. Factors influencing distant recurrence of hepatocellular carcinoma following combined radiofrequency ablation and transarterial chemoembolization therapy in patients with hepatitis C. Cancer Manag Res. 2011;3:267-272.

7. Forner A, Reig M, de Lope CR, Bruix J. Current strategy for staging and treatment: the BCLC update and future prospects. Semin Liver Dis. 2010;30:61-74.

8. Abdalla E, Denys A, Hasegawa K, et al. Treatment of large and advanced hepatocellular carcinoma. Ann Surg Oncol. 2008;15(4):979-985.

9. Chang YJ, Chung KP, Chang YJ, Chen LJ. Long-term survival of patients undergoing liver resection for very large hepatocellular carcinomas. $\mathrm{Br}$ J Surg. 2016;103:1513-1520.

10. Vitale A, Burra P, Frigo AC, et al; Italian Liver Cancer (ITA.LI.CA) group. Survival benefit of liver resection for patients with hepatocellular carcinoma across different Barcelona Clinic Liver Cancer stages: a multicentre study. J Hepatol. 2015;62:617-624.

11. Ishizawa $\mathrm{T}$, Hasegawa $\mathrm{K}$, Aoki $\mathrm{T}$, et al. Neither multiple tumors nor portal hypertension are surgical contraindications for hepatocellular carcinoma. Gastroenterology. 2008;134:1908-1916.

12. Han KQ, He XQ, Ma MY, et al. Inflammatory microenvironment and expression of chemokines in hepatocellular carcinoma. World J Gastroenterol. 2015;21(16):4864-4874.

13. Yu J, Ren X, Chen Y, et al. Dysfunctional activation of neurotensin/ IL-8 pathway in hepatocellular carcinoma is associated with increased inflammatory response in microenvironment, more epithelial mesenchymal transition in cancer and worse prognosis in patients. PLoS One 2013;8(2):e56069.

14. Shao YY, Lin H, LiYS, et al. High plasma interleukin-6 levels associated with poor prognosis of patients with advanced hepatocellular carcinoma. Jpn J ClinOncol.2017;47(10):949-953.

15. Zhu Y, Li JH, Yang J, Gao XM, Jia HL, Yang X. Inflammation-nutrition scope predicts prognosis of early-stage hepatocellular carcinoma after curative resection. Medicine (Baltimore). 2017;96(39):e8056.

16. Grivennikov SI, Greten FR, Karin M. Immunity, inflammation, and cancer. Cell. 2010;140(6):883-899.

17. Zhang J, Zhang HY, Li J, et al. The elevated NLR, PLR and PLT may predict the prognosis of patients with colorectal cancer: a systematic review and meta-analysis. Oncotarget. 2017;8(40):68837-68846.

18. Lieto E, Galizia G, Auricchio A, et al. Preoperative neutrophil to lymphocyte ratio and lymphocyte to monocyte ratio are prognostic factors in gastric cancers undergoing surgery. J Gastrointest Surg. 2017; 21(11): 1764-1774.

19. Yin Y, Wang J, Wang X, et al. Prognostic value of the neutrophil to lymphocyte ratio in lung cancer: A meta-analysis. Clinics (Sao Paulo). 2015;70(7): 524-530.

20. Yang JJ, Hu ZG, Shi WX, Deng T, He SQ, Yuan SG. Prognostic significance of neutrophil to lymphocyte ratio in pancreatic cancer: a meta-analysis. World J Gastroenterol. 2015;21(9):2807-2815. 
21. Lu SD, Wang YY, Peng NF et al. Preoperative ratio of neutrophils to lymphocytes predicts postresection survival in selected patients with early or intermediate stage hepatocellular carcinoma. Medicine (Baltimore). 2016;95(5):e2722.

22. Dan J, Zhang Y, Peng Z, et al. Postoperative neutrophil-to-lymphocyte ratio change predicts survival of patients with small hepatocellular carcinoma undergoing radiofrequency ablation. PloS One 2013;8: e58184.

23. Fan W, Zhang Y, Wang Y, et al. Neutrophil-to-lymphocyte and platelet-tolymphocyte ratios as predictors of survival and metastasis for recurrent hepatocellular carcinoma after transarterial chemoembolization. PloS One 2015;10:e0119312.

24. Limaye AR, Clark V, Soldevila-Pico C, et al. Neutrophil-lymphocyte ratio predicts overall and recurrence-free survival after liver transplantation for hepatocellular carcinoma. Hepatol Res. 2013;43:757-764.

25. da Fonseca LG, Barroso-Sousa R, Bento Ada S, et al. Pre-treatment neutrophil-to-lymphocyte ratio affects survival in patients with advanced hepatocellular carcinoma treated with sorafenib. Med Oncol. 2014;31:264

26. Mano Y, Shirabe K, Yamashita Y, et al. Preoperative neutrophil-to-lymphocyte ratio is a predictor of survival after hepatectomy for hepatocellular carcinoma: a retrospective analysis. Ann Surg 2013;258:301-305.

27. Kinoshita A, Onoda H, Imai N, et al. Comparison of the prognostic value of inflammation-based prognostic scores in patients with hepatocellular carcinoma. Br J Cancer. 2012;107:988-993.

28. Fu SJ, Shen SL, Li SQ, et al. Prognostic value of preoperative peripheral neutrophil-to-lymphocyte ratio in patients with HBV associated hepatocellular carcinoma after radical hepatectomy. Med Oncol. 2013 30:721.

29. Liao W, Zhang J, Zhu Q, et al. Preoperative neutrophil-to lymphocyte ratio as a new prognostic marker in hepatocellular carcinoma after curative resection. Transl Oncol. 2014;7:248-255.

30. Sullivan KM, Groeschl RT, Turaga KK, et al. Neutrophil-to lymphocyte ratio as a predictor of outcomes for patients with hepatocellular carcinoma: a Western perspective. J Surg Oncol. 2014;109:95-97.

31. Gomez D, Farid S, Malik HZ, et al. Preoperative neutrophil-tolymphocyte ratio as a prognostic predictor after curative resection for hepatocellular carcinoma. World J Surg. 2008;32:1757-1762.

32. van Meer S, van Erpecum KJ, Sprengers D, et al. Hepatocellular carcinoma in cirrhotic versus noncirrhotic livers: results from a large cohort in the Netherlands. Eur J Gastroenterol Hepatol. 2016;28(3):352-359.

33. Beard RE, Hanto DW, Gautam S, Miksad RA. A comparison of surgical outcomes for noncirrhotic and cirrhotic hepatocellular carcinoma patients in a Western institution. Surgery. 2013;154(3):545-555.

34. European Association for Study of the Liver, European Organisation for Research and Treatment of Cancer. EASL-EORTC clinical practice guidelines: management of hepatocellular carcinoma. Eur J Cancer. 2012;48(5):599-641.

35. Milicevic M, Bulajic P, Zuvela M, Dervenis C, Basarić D, Galun D. A radiofrequency-assisted minimal blood loss liver parenchyma dissection technique. Dig Surg. 2007;24(4):306-313.

36. Galun D, Bulajic P, Zuvela M.Basaric D, Ille T, Milicevic MN. Is there any benefit from expanding the criteria for the resection of hepatocellular carcinoma in cirrhotic liver? Experience from a developing country. World J Surg. 2012;36(7):1657-1665.

37. Pang YY. The Brisbane 2000 terminology of liver anatomy and resections. HPB. 2000;2:333-339.

38. Bronson N, Enestvedt K, Thomas E, et al. Preoperative neutrophil to lymphocyte ratio does not predict recurrence or prognosis after resection for hepatocellular carcinoma. HPB. 2012;14:456.
39. Pollard JW. Tumour-educated macrophages promote tumour progression and metastasis. Nat Rev Cancer. 2004;4:71-78.

40. Coussens LM, Werb Z. Inflammation cancer. Nature. 2002;420:860-867.

41. Wu Y, Zhao Q, Peng C, Sun L, Li XF, Kuang DM. Neutrophils promote motility of cancer cells via a hyaluronan-mediated TLR4/PI3K activation loop. J Pathol. 2011;225:438-447.

42. McDonald B, Spicer J, Giannais B, Fallavollita L, Brodt P, Ferri LE. Systemic inflammation increases cancer cell adhesion to hepatic sinusoids by neutrophil mediated mechanisms. Int J Cancer 2009;125:1298-1305.

43. Kusumanto YH, Dam WA, Hospers GA, Meijer C, Mulder NH. Platelets and granulocytes, in particular the neutrophils, form important compartments for circulating vascular endothelial growth factor. Angiogenesis. 2003;6:283-287.

44. Muller I, Munder M, Kropf P, Hänsch GM. Polymorphonuclear neutrophils and T lymphocytes: strange bedfellows or brothers in arms? Trends Immunol. 2009;30:522-530.

45. Schreiber RD, Old LJ, Smyth MJ. Cancer immunoediting: integrating immunity's roles in cancer suppression and promotion. Science. 2011;331:1565-1570.

46. Svennevig JL, Lunde OC, Holter J, Bjorgsvik D. Lymphoid infiltration and prognosis in colorectal carcinoma. Br J Cancer. 1984;49:375-377.

47. Okano K, Maeba T, Moroguchi A, et al. Lymphocytic infiltration surrounding liver metastases from colorectal cancer. J Surg Oncol. 2003;82: 28-33.

48. Tretiakova MS, Shabani-Rad MT, Guggisberg K, Hart J, Anders RA, Gao ZH. Genomic and immunophenotypical differences between hepatocellular carcinoma with and without cirrhosis. Histopathology. 2010;56:683-693.

49. Young AL, Adair R, Prasad KR, et al. Hepatocellular carcinoma within a noncirrhotic, nonfibrotic, seronegative liver: surgical approaches and outcomes. J Am Coll Surg. 2012;214:174-183.

50. Zheng J, Cai J, Li H, et al. Neutrophil to lymphocyte ratio and platelet to lymphocyte ratio as prognostic predictors for hepatocellular carcinoma patients with various treatments: a meta-analysis and systematic review. Cell Physiol Biochem. 2017;44(3):967-981.

51. Wang Q, Blank S, Fiel MI, et al. The severity of liver fibrosis influences the prognostic value of inflammation-based scores in hepatitis B-associated hepatocellular carcinoma. Ann Surg Oncol 2015;22:S1125-S1 132

52. Paradis V, Zalinski S, Chelbi E, et al. Hepatocellular carcinomas in patients with metabolic syndrome often develop without significant liver fibrosis: a pathological analysis. Hepatology. 2009;49:851-859.

53. Browning JD, Horton JD. Molecular mediators of hepatic steatosis and liver injury. J Clin Invest. 2004;114:147-152.

54. Reuter S, Gupta SC, Chaturvedi MM, Aggarwal BB. Oxidative stress, inflammation, and cancer: how are they linked? Free Radic Biol Med. 2010;49:1603-1616.

55. Najjar M, Agrawal S, Emond JC, Halazun KJ. Pretreatment neutrophillymphocyte ratio: useful prognostic biomarker in hepatocellular carcinoma. J Hepatocell Carcinoma. 2018;5:17-28.

56. Coussens LM, Werb Z. Inflammation cancer. Nature. 2002;420:860-867.

57. Fenwick SW, Toogood GJ, Lodge JP, Hull MA. The effect of the selective cyclooxygenase-2 inhibitor rofecoxib on human colorectal cancer liver metastases. Gastroenterology. 2003;125:716-729.

58. Lesterhuis WJ, de Vries IJ, Schuurhuis DH, et al. Vaccination of colorectal cancer patients with CEA-loaded dendritic cells: antigen-specific T cell responses in DTH skin tests. Ann Oncol. 2006;17(6):974-980.

59. Xu XS, Wan Y, Song SD, et al. Model based on $\gamma$-glutamyltransferase and alkaline phosphatase for hepatocellular carcinoma prognosis. World J Gastroenterol.2014;20(31):10944-10952. 


\section{Publish your work in this journal}

Cancer Management and Research is an international, peer-reviewed open access journal focusing on cancer research and the optimal use of preventative and integrated treatment interventions to achieve improved outcomes, enhanced survival and quality of life for the cancer patient. The manuscript management system is completely online and includes a very quick and fair peer-review system, which is all easy to use. Visit http://www.dovepress.com/testimonials.php to read real quotes from published authors.

Submit your manuscript here: https://www.dovepress.com/cancer-management-and-research-journal 